\title{
Echocardiographic diagnosis of primitive ventricle with two atrioventricular valves
}

\author{
JUDITH A. BEARDSHAW, DEREK G. GIBSON, MICHAEL C. PEARSON, \\ MARK T. UPTON, ${ }^{1}$ AND ROBERT H. ANDERSON ${ }^{2}$ \\ From the Departments of Paediatrics, Cardiology, and Radiology, Brompton Hospital, \\ Fulham Road, London
}

\begin{abstract}
Anatomical studies have shown that the pathognomonic feature of primitive ventricle is absence of that portion of the interventricular septum which interposes between the atrioventricular valves. The relation of this posterior septum to the atrioventricular valves is such that echocardiography should be a particularly suitable technique for showing its presence or absence. When a posterior septum is present, it is seen on an echocardiogram as a double echo between the two atrioventricular valves. Its presence limits posterior movement of the septal cusp of the anterior atrioventricular valve. Absence of the posterior septum should, therefore, be seen echocardiographically as more than mere absence of the double septal echo. It should be possible to show unusual posterior excursion of the 'septal' cusp of the anterior atrioventricular valve and apposition of the 'septal' cusps of the atrioventricular valves during diastole. In most instances it should also be possible to demonstrate that the posterior great artery is in continuity with both atrioventricular valves. We have shown these echocardiographic features in 26 patients. The diagnosis of primitive ventricle has been confirmed at necropsy or at operation in 4 patients. In the other 22 patients the angiographic data are compatible with a diagnosis of primitive ventricle. Demonstration of these positive features at echocardiography is, therefore, of considerable value in the initial diagnosis of primitive ventricle and in particular its differentiation from other congenital malformations.
\end{abstract}

Surgical techniques for the correction of complicated congenital heart defects have been improving rapidly over the past decade. However, one anomaly that continues to pose problems, both in diagnosis and surgical correction, is the univentricular heart which we prefer to describe as primitive ventricle (Anderson et al., 1976). Recently, there have been reports of successful correction, both by septation (Edie et al., 1973; Maloney et al., 1975) and by the use of valved conduits (Yacoub et al., 1975). It has emerged from these reports that success or failure of surgical correction depends on an accurate preoperative knowledge of the anatomy. However, in our experience, this is a condition which can be difficult to diagnose, even after angiography. Absence of the posterior interventricular septum (the hallmark of primitive ventricle) can sometimes be difficult to demonstrate, while in other instances it is not possible to determine the

'Present address: Mark Hitchcock Memorial Hospital, Hanover, New Hampshire 03755, USA.

${ }^{2}$ R.H.A. is a British Heart Foundation Senior Research Fellow. Received for publication 27 August 1976 number of atrioventricular valves present, both being features of considerable surgical importance. During an anatomical study currently in progress it became evident that echocardiography should be a suitable technique for establishing the diagnosis of primitive ventricle, since these hearts have more features amenable to echocardiographic identification than mere absence of the posterior septum. A specific study of morphology has therefore been undertaken to determine precise positive features of the anomaly that might be demonstrable using $M$ mode echocardiography. The clinical, angiographic, surgical, and necropsy data have then been correlated in patients with these echocardiographic features.

\section{Materials and methods}

\section{(a) ANATOMICAL STUDY}

Seventy-three hearts were studied in which there was absence of that part of the septum separating the atrioventricular valves. These hearts were compared with the normal. The specimens were taken 
from various cardiopathological collections, namely from Brompton Hospital, London; Royal Liverpool Children's Hospital; Southampton Western Hospital; Killingbeck Hospital, Leeds; The Hospital for Sick Children, London; and Grimsby General Hospital; University of Amsterdam; University of Leiden and Sint Antonius Ziekenhuis, Utrecht.

\section{(b) ECHOCARDIOGRAPHIC STUDY}

An M-mode echocardiogram was performed on 75 patients in whom a diagnosis of univentricular heart was suspected on clinical grounds. These included patients suspected of having atrioventricular valve atresia, which is in our opinion better considered as a type of univentricular heart, and other patients in whom the differential diagnosis was large ventricular septal defect or 'corrected transposition'. Recordings were made with a Smith-Kline Ekoline 20A echocardiograph interfaced with either a Honeywell fibreoptic strip chart recorder, or a Cambridge photographic strip chart recorder. A $2.25 \mathrm{MHz}$ transducer was used in all patients other than neonates in whom a $5 \mathrm{MHz}$ transducer was occasionally used. There were 26 patients whose echocardiograms showed the features which we considered to be diagnostic of primitive ventricle with two atrioventricular valves; these patients formed the basis of the study. The angiograms and catheterisation data of these patients were reviewed and compared with the echocardiographic findings. In those patients who subsequently had an operation or died, direct anatomical comparison was made.

\section{Results}

(a) ANATOMICAL CONSIDERATIONS

The common feature of the 73 hearts studied (Table) was complete absence of any posterior septal structure separating the septal cusps of the right and left atrioventricular valves (Fig. 1). In all the hearts the right and left valves closely resembled each other in terms of cusp pattern, each valve possessing a prominent 'septal' cusp (Fig. 2B). In all except one of the hearts studied, both of these 'septal' cusps were free to move into the outflow tract of the posterior great artery, this observation suggesting that during ventricular diastole during life the cusps would have been free to approximate each other in this posterior arterial outflow tract (Fig. 2A); in the other heart, both great arteries arose from an outlet chamber.

Though the ventricular inflow portions of all the hearts were identical, the hearts could be subdivided depending on the presence or absence of an anterior septal structure. Such a structure,
Table Details of 73 anatomical specimens studied

\begin{tabular}{|c|c|c|}
\hline $\begin{array}{l}\text { Primitive ventricle with outlet chamber: } \\
\qquad \text { I }\left\{\begin{array}{l}\text { both valves entirely to main chamber } \\
\text { straddling right AV valve } \\
\text { straddling left AV valve }\end{array}\right.\end{array}$ & $\begin{array}{r}46 \\
8 \\
5\end{array}$ & 59 \\
\hline II $\left\{\begin{array}{l}\text { outlet chamber to right } \\
\text { outlet chamber anterior } \\
\text { outlet chamber to left }\end{array}\right.$ & $\begin{array}{r}28 \\
4 \\
27\end{array}$ & \\
\hline III $\left\{\begin{array}{l}\text { normal connections } \\
\text { l-transposition } \\
\text { d-transposition } \\
\text { double-outlet main chamber } \\
\text { double-outlet outlet chamber } \\
\text { single aortic trunk with pulmonary atresia }\end{array}\right.$ & $\begin{array}{r}10 \\
27 \\
16 \\
3 \\
1 \\
2\end{array}$ & \\
\hline $\begin{array}{l}\text { Primitive ventricle without outlet chamber: } \\
\qquad\left\{\begin{array}{l}\text { d-malposition ('normal relations') } \\
\text { d-malposition ('side-by-side') } \\
\text { l-malposition ('side-by-side') }\end{array}\right.\end{array}$ & $\begin{array}{l}5 \\
4 \\
5\end{array}$ & 14 \\
\hline
\end{tabular}

Note: These hearts were studied as part of an ongoing investigation; further details are to be published at a later date (Anderson, Wilkinson, and Becker, unpublished observations).

smooth on its posterior aspect (Fig. 2B), was present in 59 hearts, dividing the ventricular segment of these hearts into a larger portion receiving the atrioventricular valves, the primitive ventricle, and a smaller portion which usually gave rise to a single great artery but did not contain atrioventricular valvar tension apparatus; we have termed this anterior chamber the outlet chamber. The septum separating the primitive ventricle from the outlet chamber was always situated anteriorly to both atrioventricular valves, though occasionally it was straddled by one of these valves. When straddling occurred (in 13 hearts), then some tension apparatus took origin from the outlet chamber. Though smooth on its posterior aspect, the septum was in no way comparable to the septum observed in the normal heart (Fig. 1 and 4). It never extended posteriorly to the crux of the heart, always tending to run to the margo acutus in primitive ventricular hearts (Fig. 2 and 3). Furthermore, in primitive ventricular hearts (Fig. 2 and 3 ) it never supported the septal cusp of the right atrioventricular valve, as it does in the normal heart (Fig. 4). In the primitive ventricles with outlet chamber, there was variation in the orientation of the anterior septum. In 28 hearts, the septum ran from a left anterior position in posterior direction to the margo acutus at the right border of the heart (Fig. 3): in these, the small trabeculated tail of the outlet chamber was also to the right. In $\mathbf{4}$ hearts the septum was directly in the frontal plane, placing the outlet chamber anterior to the primitive ventricle; in 3 of these the tail was left-sided and in one right-sided. In 27 hearts the septum ran from right anterior obliquely and posteriorly to the left margin of the heart, with the tail 
also to the left (Fig. 2). In the 13 hearts with a straddling valve, the outlet chamber was of larger dimensions and the septum was straddled by the anterior papillary muscle and anterior cusp of the valve. In 8 hearts the right atrioventricular valve straddled into a right-sided outlet chamber (Fig. 3). In 5 hearts the left-sided valve was the straddling valve, with the outlet chamber to the left in 4 and to the right in 1 . Despite this straddling, the relation of the septal cusps of both atrioventricular valves to the posterior great artery was as in all the other primitive ventricular hearts (Fig. 3).

In the 14 hearts without an anterior septal structure dividing the ventricular cavity into main chamber and outlet chamber, a single ventricular chamber received both atrioventricular valves and supported both great arteries (except when one great artery was atretic). In terms of trabecular pattern, apart from the absence of the anterior septum, the hearts were identical with those which possessed outlet chambers. We have, therefore, termed these hearts primitive ventricle without outlet chamber. In 5 of these hearts the left part of the anterior septum fused with the infundibular septum to produce a well-formed infundibular chamber (Fig. 5). However, the septum did not extend apically to separate the infundibulum as part of a discrete outlet chamber.

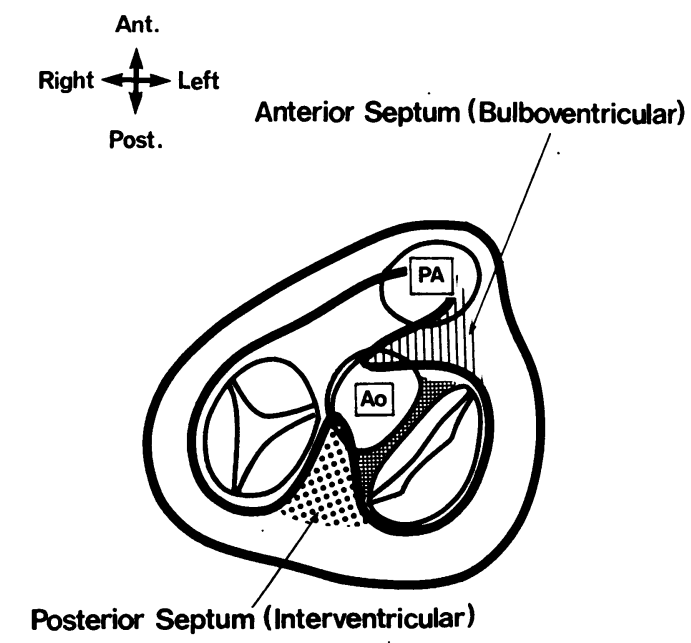

In all the examples of primitive ventricle without outlet chamber, since the ventricle was a single chamber, the ventriculoarterial connection must by definition be one of double-outlet chamber. In primitive ventricle with outlet chamber, more variation was observed in ventriculoarterial connections (Table). In 10 hearts the arteries were normally connected; in 27 hearts 1-transposition was present; in $16 \mathrm{~d}$-transposition was observed; 3 hearts had double outlet main chamber, 1 heart possessed a double-outlet outlet chamber, and the remaining 2 hearts had single aortic trunks from the outlet chamber with pulmonary atresia. These variations in ventriculoarterial connection in no way affected the atrioventricular valves except to produce some alteration in the state of the ventriculoinfundibular fold. The posterior great artery arose from muscular tissue in only 8 of 73 hearts, and 6 of these had a double-outlet connection. In 9 hearts the posterior great artery was in fibrous continuity with only one atrioventricular valve, the right in 5 and the left in 4 . In the remaining 56 hearts $(77 \%)$ the posterior great artery was in fibrous continuity with both atrioventricular valves.

Thus, from this anatomical study we would expect that, in addition to absence of the posterior septum, other positive features of primitive ventricle would be identifiable echocardiographically.

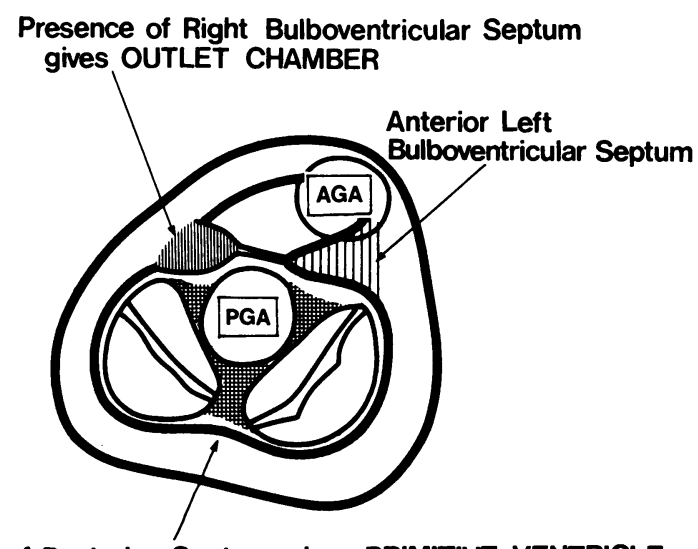

Absence of Posterior Septum gives PRIMITIVE VENTRICLE

Fig. 1 Cross-sectional diagrams comparing the septal components of the normal heart (left hand diagram) with primitive ventricle (right hand diagram). In the normal heart the muscular septum has two components; an anterior, bulboventricular septum between the infundibulum and the left ventricle and a posterior, interventricular component between the atrioventricular valves. Absence of this posterior septal component gives the univentricular heart, termed by us 'primitive ventricle'. If the anterior bulboventricular septum persists in its entirety, then the primitive ventricle will be associated with an outlet chamber. Should the right portion of the bulboventricular septum be absent, then primitive (single or common) ventricle without outlet chamber will result. 
These are (a) free 'septal' excursion of the right atrioventricular valve; (b) apposition of the 'septal' valve cusps in ventricular diastole, and (c) in the majority of hearts continuity of the posterior great artery with both atrioventricular valves (Fig. 6).

(b) ECHOCARDIOGRAPHIC DATA

Between January 1975 and March 1976, 75 patients in whom a diagnosis of primitive ventricle was either suspected or considered as a differential diagnosis, underwent echocardiographic study at the Brompton Hospital. Of these patients 26 fulfilled the expected criteria for primitive ventricle with two atrioventricular valves. All 26 patients showed (a) absence of a posterior interventricular septum between the two atrioventricular valves, (b) unusual posterior excursion of the posterior cusp of the anterior atrioventricular valve which closely resembled the posterior atrioventricular valve, and (c) apposition of the 'septal' cusps of the two atrioventricular valves during diastole (Fig. 7). In 25 patients there was echocardiographic 'continuity' between the two atrioventricular valves and the posterior semilunar valve (Fig. 8 and 9). An anterior (anatomically bulboventricular) septum was found with certainty in only 7 patients.

The diagnosis of primitive ventricle with or without outlet chamber was confirmed at operation or necropsy in 4 patients. Three of these patients had been diagnosed angiographically as primitive

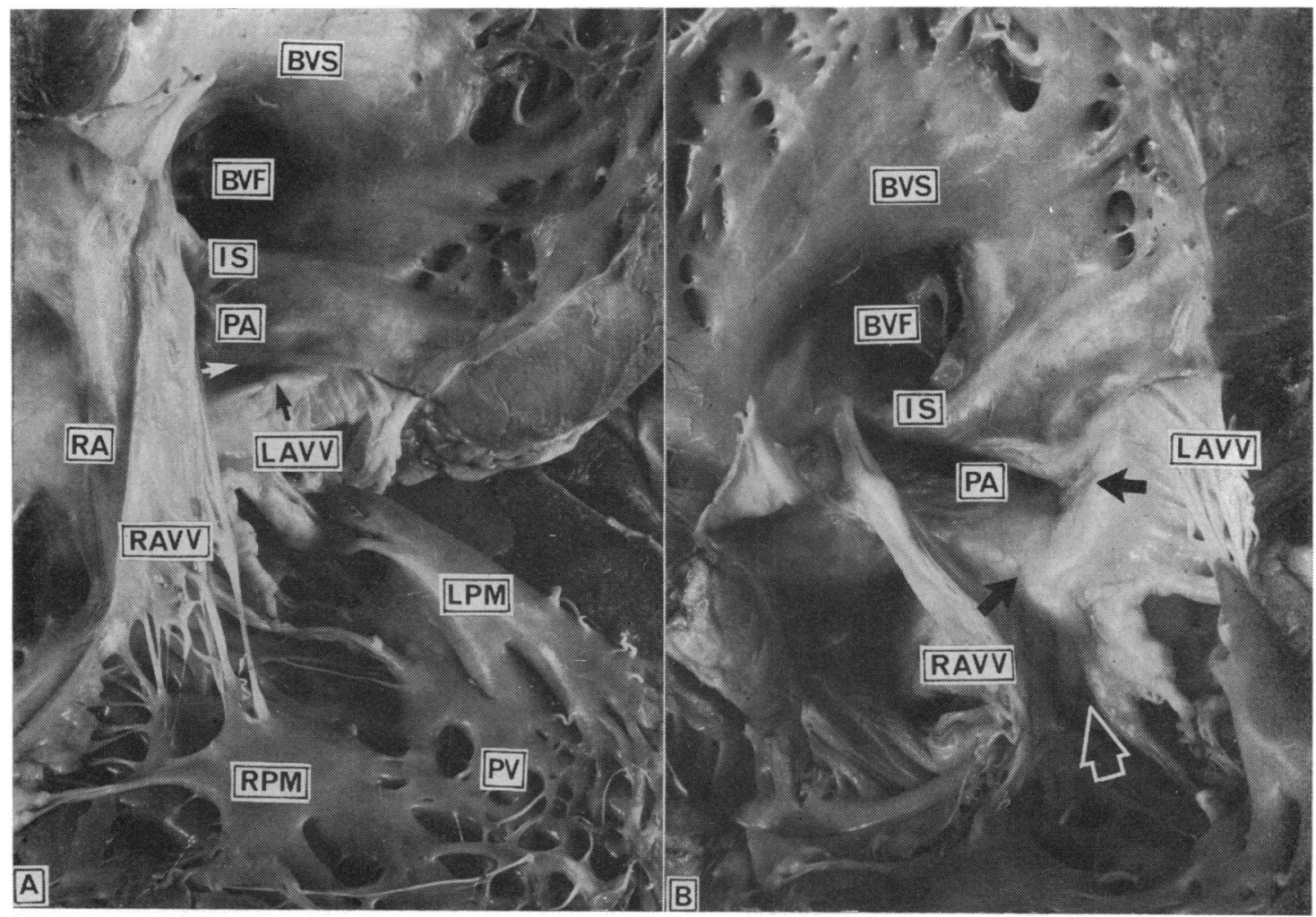

Fig. 2 (A) Photograph of the primitive ventricle from a specimen of primitive ventricle with outlet chamber. The heart has been opened by a frontal cut through the primitive ventricle (PV), which receives both atrioventricular valves (RAVV, LAVV), and the anterior aspect has been reflected superiorly so that the bulboventricular septum $(B V S)$ and the bulboventricular foramen (BVF) are seen in the top of the picture. Through the bulboventricular foramen part of the outlet chamber can be seen. The infundibular septum (IS) separates the pulmonary artery (PA) from the aorta which arises from the outlet chamber. Note that both atrioventricular valves are free to move into the outflow tract of the posterior great artery (arrows). LPM, left-sided papillary muscle; RPM, right-sided papillary muscle; $R A$, right atrium. (B) Another view of the same heart, with retraction of the 'septal' cusp of the right atrioventricular valve. The absence of the posterior septum is now evident (large arrow) and the potential for free movement of both atrioventricular valves into the outflow tract of the posterior artery is clearly seen (small arrows). 
ventricle. The fourth patient had been diagnosed angiographically as double-outlet right ventricle, but the echocardiogram (Fig. 9) showed the features of primitive ventricle, and at operation this latter diagnosis was confirmed.

Of the remaining 22 patients, 16 had originally been diagnosed as primitive ventricle with or without outlet chamber. Four had been diagnosed as 'corrected transposition' (the combination of transposition and atrioventricular discordance). In 2 further patients the differential diagnosis was between transposition with ventricular septal defect and a primitive ventricle, and 2 had been given no definite diagnosis. As a result of our anatomical study, we were able to review the angiograms with the morphological features of primitive ventricle in mind, and look for the specific diagnostic features. Thus, an angiographic diagnosis of primitive ventricle was made if there was definite evidence of 2 atrioventricular valves entering the same ventri- cular chamber. The relation of the posterior great artery to the main chamber was particularly helpful in this respect, since in primitive ventricle the artery arises from the mid-point of the chamber, being contiguous with both atrioventricular valves. In the presence of a posterior septum, the origin of the posterior great artery is eccentric. We also felt that we were able to distinguish between an outlet chamber and a morphologically right ventricle on angiographic appearances, the former being smaller, possessing less of an apical trabeculated segment, and never receiving the entirety of an atrioventricular valve. Using these criteria the angiograms were found to be compatible with a diagnosis of primitive ventricle in all these 22 patients.

The angiograms showed an outlet chamber in 13 patients; in only $7(54 \%)$ of these was an anterior septum detected echocardiographically. However, in no case was an anterior septum shown on the echocardiogram, where an outlet chamber was not

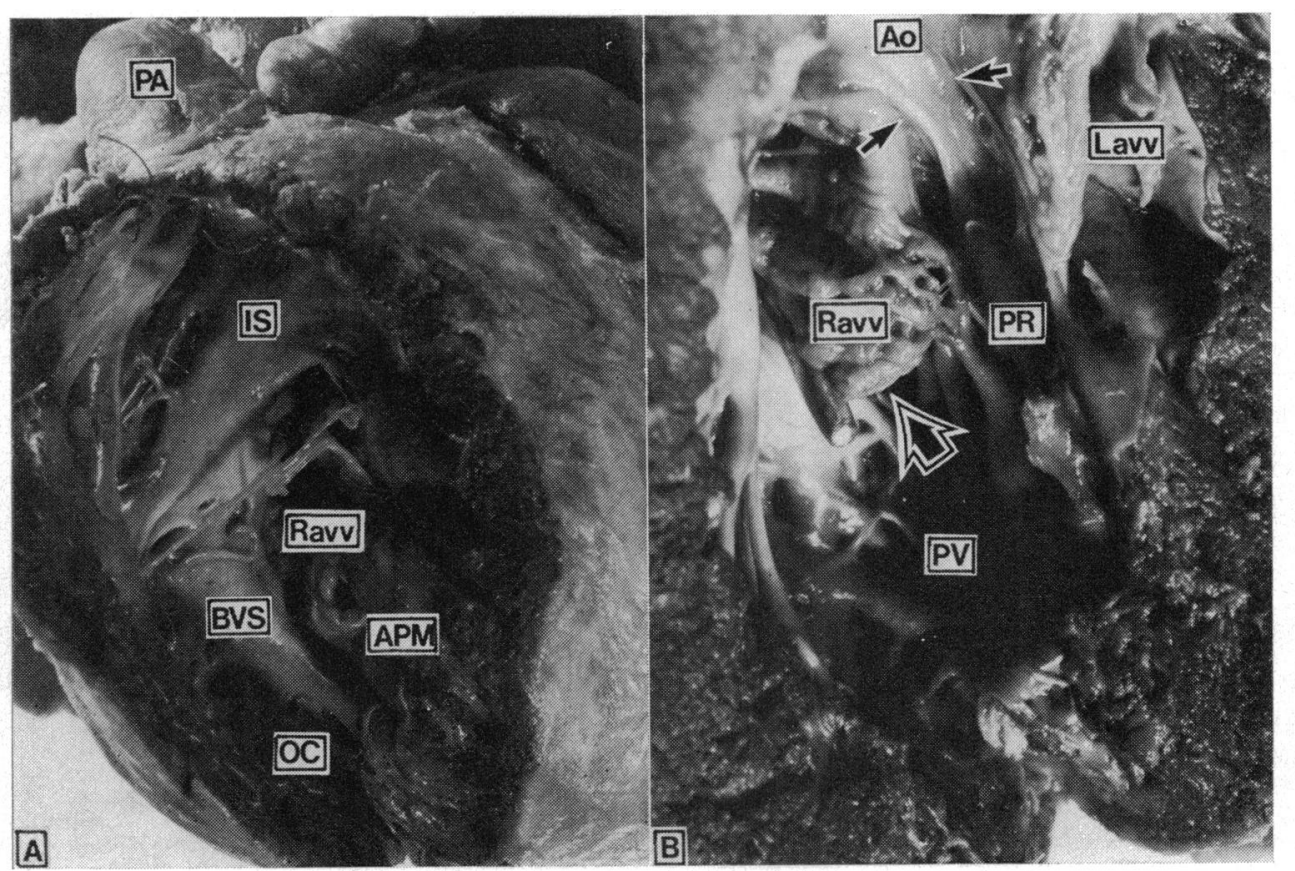

Fig. 3 Photographs of an example of primitive ventricle with outlet chamber and straddling right atrioventricular valve. Fig. $3 A$ is a view of the outlet chamber (OC), which supports the normally connected pulmonary artery (PA). Note that the anterior bulboventricular septum (BVS) runs from left anterior in posterior direction to the right acute margin of the heart where it fuses with the infundibular septum (IS). It is straddled by the anterior papillary muscle (APM) of the right $A V$ valve (Ravv). Fig. $3 B$ shows the primitive ventricle (PV), which receives the entirety of the left atrioventricular valve (Lavv) and the greater part of the right valve. Note that the 'septal' cusp of the right valve is tethered into the primitive ventricle, and that both cusps are free to move into the aortic outflow tract (small arrows) where they are in fibrous continuity with the aortic valve. Note that the septum (large arrow) runs to the acute margin of the ventricle and does not interpose between the atrioventricular valves. In the anticipated site of the posterior septum a well-formed posterior ridge $(P R)$ is present. 
present on the angiogram. One patient was found at necropsy to have a straddling right atrioventricular valve; this was not apparent on either the echocardiogram or the angiogram. The angiograms of one other patient also suggested a straddling right atrioventricular valve, but this was not shown on the echocardiogram.

\section{Discussion}

Previous echocardiographic studies have shown that absence of septal echoes may indicate presence of a single (primitive) ventricle (Chesler et al., 1971; Meyer and Kaplan, 1973; Assad-Morrell et al., 1974; Ferrer et al., 1975; Felner et al., 1976; Seward et al., 1976). However, since it is possible to miss septal echoes in a heart containing a septum the condition may be incorrectly diagnosed. Our study has shown that there are positive features of the primitive ventricle that can be seen in addition to absence of the septum, so that echocardiographic diagnosis can be based on positive rather than negative findings. Our anatomical study confirmed that the cardinal feature of the primitive ventricle is absence of the posterior portion of the interventricular septum (Van Praagh et al., 1964; Lev et al., 1969). It also showed that absence of this septum affects the movements of the atrioventricular valves in such a way as to give a characteristic echocardiographic pattern, namely: (a) unusual posterior excursion of the posterior cusp of the anterior atrioventricular valve so that it closely resembles the posterior valve, (b) apposition of the septal cusps of the two atrioventricular valves, and (c) in the majority of cases echocardiographic continuity between the posterior semilunar valve and the two atrioventricular valves. Thus, if diagnosis is based on these findings, false positive diagnoses should be prevented (should it merely have not proved possible to echo a normally positioned posterior septum), and false negatives should be avoided in the circumstance of large conjoined papillary muscles giving the angiographic appearance of a posterior septum. The finding of continuity of the posterior great artery with both atrioventricular valves is perhaps more difficult to establish than the other criteria. Furthermore, since absolute continuity of adjacent fibrous structures is difficult to establish echocardiographically, it may seem of less value. None the less, Seward et al. (1976) showed echocardiographic continuity of the posterior great artery with the posterior atrioventricular valve in 27 of 31 patients, while Felner et al. (1976) observed this feature in 5 of 6 patients. Since anatomical continuity of the posterior great artery with both atrioventricular valves was seen in 77 per cent of our necropsy specimens, with continuity of one valve and contiguity of the other in a further 14.5 per cent, we believe the finding to be of considerable significance if the term contiguity is used rather than continuity. Thus, there are very few other congenital anomalies apart from primitive ventricle which would present the feature of both atrioventricular valves in contiguity with the posterior great artery in the absence of a posterior septum.

In our study the echocardiograms of 26 patients showed these anticipated features of single ventricle with two atrioventricular valves. The correlation

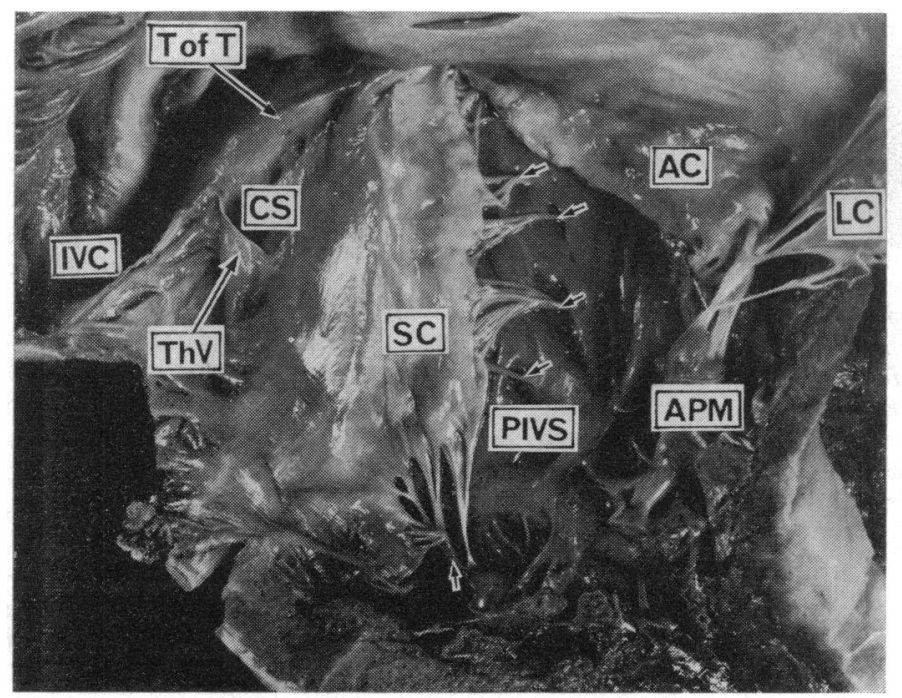

Fig. 4 Photograph of a normal heart opened through the posterior aspect of the right atrioventricular orifice with reflection of the parietal wall. Note how the septal cusp (SC) of the tricuspid valve is tethered tightly to the posterior interventricular septum (PIVS) by multiple, small chordae and papillary muscles (arrowed). The anterior (AC) and lateral (LC) cusps are tethered by the prominent anterior papillary muscle (APM). The inferior vena cava (IVC), Thebesian valve (ThV) guarding the coronary sinus (CS) and the site of the tendon of Todaro ( $T$ of $T$ ) are all visible within the right atrium. 
with angiographic, surgical, and necropsy date was good. Our attempts to identify an anterior septum and its relation to the anterior atrioventricular valve have not been entirely successful. Others have achieved greater success in this respect, and C. Mortera, S. J. Hunter, and M. J. Tynan (1976, personal communication) have positively identified outlet chambers by echocardiography in over 90 per cent of patients shown by cardiac catheterisation to have primitive ventricle with outlet chamber. An anterior septum straddled by the right atrioventricular valve has also been identified echocardiographically, by Seward et al. (1975a) and by

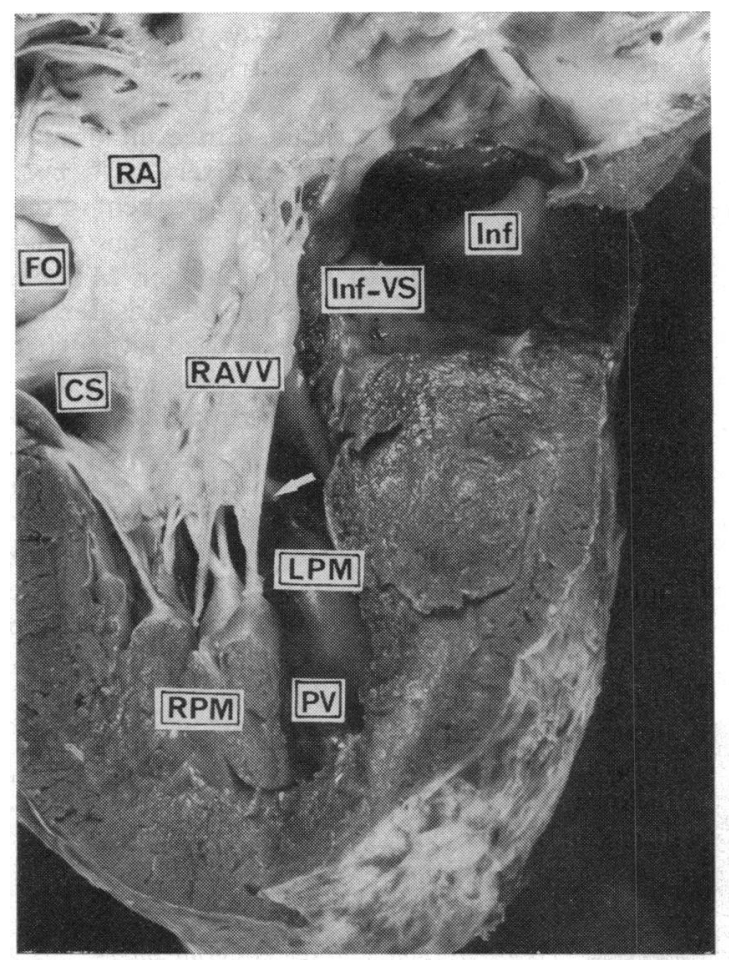

Fig. 5 Photograph of a specimen of primitive ventricle without outlet chamber, opened through a posterior cut in the right atrioventricular orifice (exactly as in Fig. 2). Though an infundibulo-ventricular septum (Inf-VS) separates the infundibulum (Inf) from that part of the heart receiving the atrioventricular valves, this septum does not continue to the right and an outlet chamber is not present. The great arteries are normally connected. Again note the absence of the posterior septum (arrowed) between the right atrioventricular valve (RAVV) with its papillary muscles (RPM) and the papillary muscle (LPM) of the left atrioventricular valve. $P V$, primitive ventricle; $C S$, coronary sinus; $F O$, foramen ovale; $R A$, right atrium.
Lacorte et al. (1976); examination of the illustrated echocardiograms from both these reports shows that they fulfil the criteria we have suggested for primitive ventricle. It is our belief that these hearts are similar to the hearts we studied and characterised as primitive ventricle with outlet chamber and straddling atrioventricular valves. It can logically be argued that if part of an atrioventricular valve enters an anterior chamber this can no longer be considered an outlet chamber. In these circumstances, as suggested by Liberthson et al. (1971), the chambers can alternatively be designated as primitive left and primitive right ventricles. Be that as it may, there is no doubt in our minds that the septum straddled in such hearts is the bulboventricular septum as in primitive ventricle with outlet chamber rather than the interventricular septum as in the normal heart; furthermore, the anterior chamber resembles an outlet chamber rather than a right ventricle.

An additional technique which may be of value in the investigation of primitive ventricle is contrast echocardiography. Using such contrast echocardiography the Mayo Clinic group have had considerable success in diagnosis (Seward et al., 1975b; J. B. Seward, 1976, personal communication). This technique should also be of value in distinguishing patients with straddling atrioventricular valves.

We thus believe that a positive diagnosis of primitive ventricle can be made echocardiographically. This is of importance since it allows the differentiation of primitive ventricle from other conditions with which it may be confused angiographically. The most significant of these is congenitally corrected transposition (transposition with atrioventricular discordance). Indeed some authors contend that primitive ventricle with left-sided outlet chamber should be considered as a variant of 'corrected transposition' (Friedberg and Nadas, 1970). We agree with Ruttenberg (1970) and believe that the two should be considered as separate anomalies, the presence or absence of a posterior septum being the distinguishing feature. This is equally true of the distinction of primitive ventricle with straddling left atrioventricular valve from corrected transposition. As we have shown, the absence of the posterior septum is particularly well demonstrated echocardiographically, while it also appears that congenitally corrected transposition itself has clearly recognisable echocardiographic features (Beardshaw et al., 1976; Rey and Lablanche, 1976; Keutel and Hagenmuller, 1976).

Finally, it must not be presumed that the echocardiogram provides all the answers. We believe that cardiac catheterisation is essential in the study of all suspected cases of primitive ventricle. This is par- 


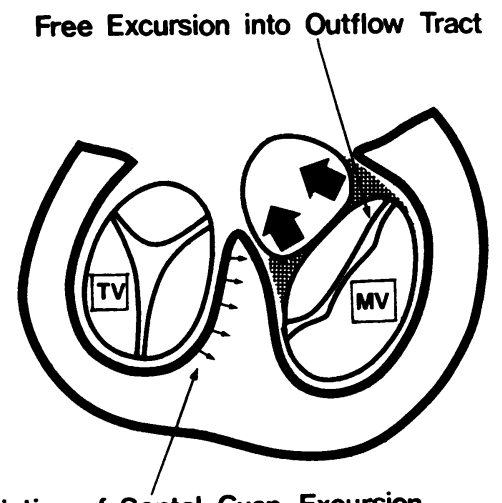

Restriction of Septal Cusp Excursion

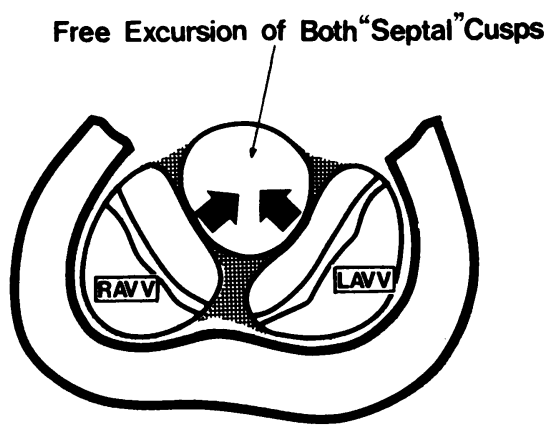

\section{(A) NORMAL HEART}

(B) PRIMITIVE VENTRICLE

Fig. 6 Diagrams showing how the anatomy illustrated in Figures 2 to 4 affects the valve movements in $(A)$ the normal heart and (B) primitive ventricle. Orientation as indicated in Fig. 1.TV, tricuspid valve; $M V$, mitral valve. Note that the morphology of the two atrioventricular valves is similar in primitive ventricle, and that they are therefore designated right (RAVV) and left (LAVV).

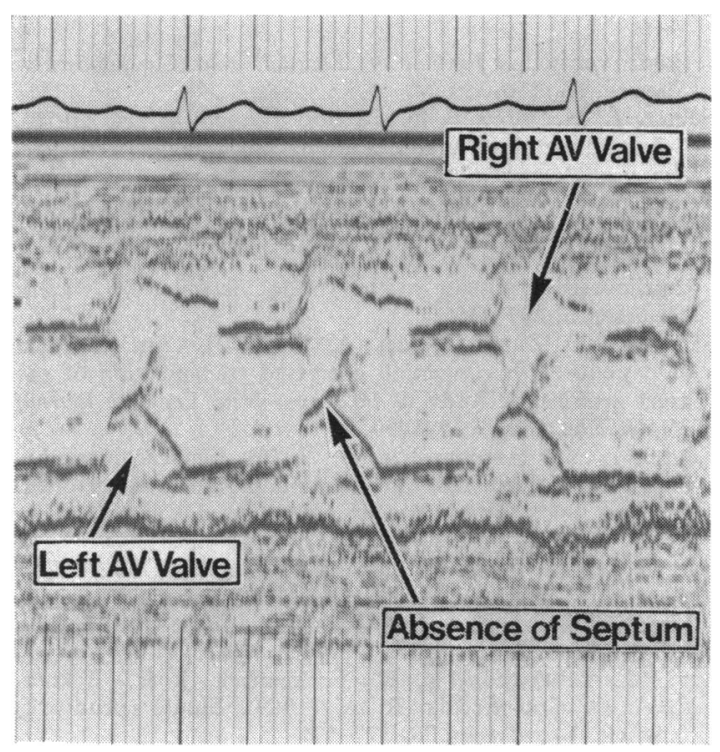

Fig. 7 Echocardiogram of primitive ventricle. Note (a) the unusual posterior excursion of the right atrioventricular valve which resembles the left atrioventricular valve, (b) the meeting of the atrioventricular valves during diastole, and (c) the absence of echoes from the posterior interventricular septum. ticularly so in order to show the presence or absence of an outlet chamber, a feature which in our hands has not so far lent itself to reliable echocardiographic delineation. In planning treatment, the presence of associated lesions, including semilunar valve stenosis, must also be established; these are also more clearly shown by conventional haemodynamic study and angiography. At the time of angiography it should also be possible to perform contrast echocardiography which, as the Mayo Clinic group have shown, gives considerably more information (Seward et al., 1975b). Using the combined techniques of echocardiography and angiography, we believe it should be possible to diagnose single ventricle accurately and provide information on the presence or absence of an outlet chamber and the number and condition of atrioventricular valves present, essential information for any subsequent operation.

We are grateful to our colleagues Drs. A. E. Becker, Wilhelmina Gasthuis, Amsterdam, and J. L. Wilkinson, University of Liverpool, for permitting us to quote pertinent details from an ongoing anatomical study of primitive ventricle. We are also grateful to our clinical colleagues, Drs. M. C. Joseph and E. A. Shinebourne, for allowing us to study patients in their care, and to Dr. G. A. H. Miller, Director, Cardiac Laboratories, Brompton Hospital. We are indebted to Dr. A. Oppen- 


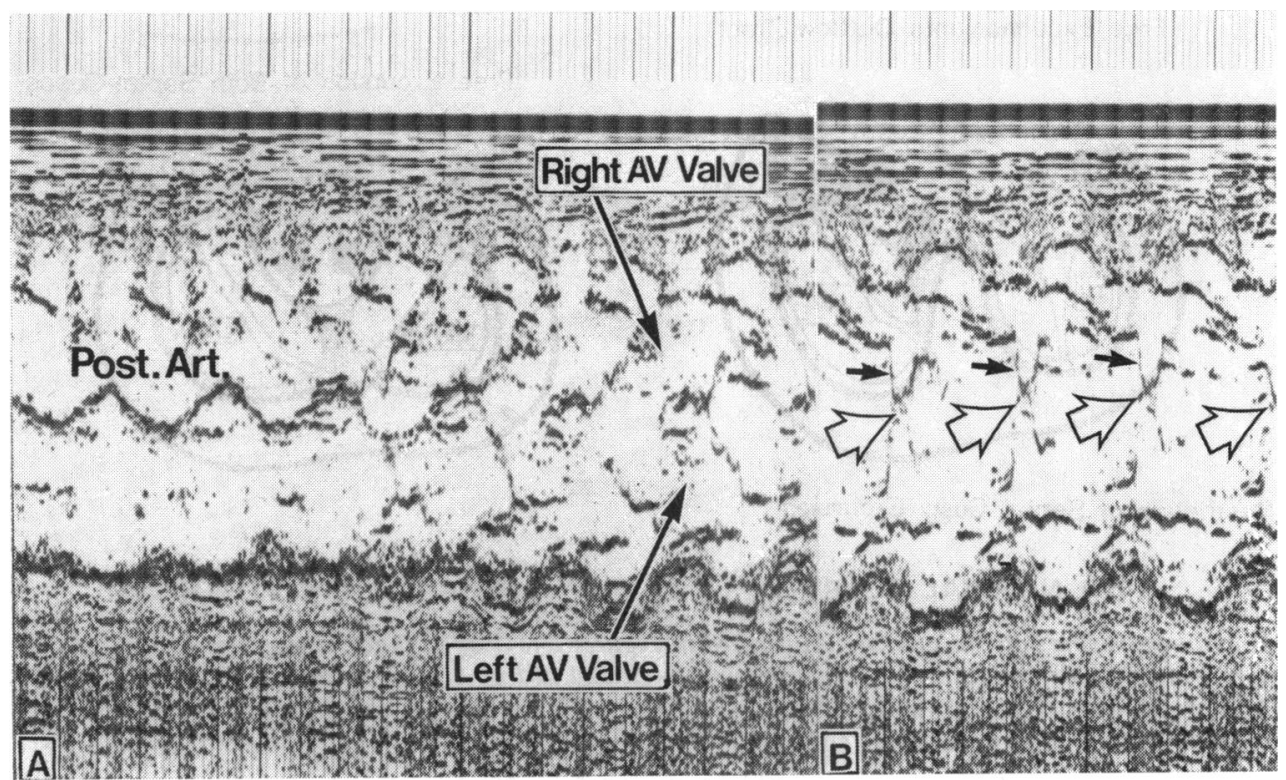

Fig. 8 (A) Echocardiogram of primitive ventricle showing a scan from the posterior artery into the right and left atrioventricular ( $A V)$ valves. There is contiguity between these structures. (B) Scan of the valves themselves illustrates meeting of the 'septal' cusps in diastole in absence of a septum (open arrows) and unusual posterior excursion of the right valve (closed arrows) so that it resembles the left valve.

heimer-Decker, Leiden, Holland; Drs. Van Gorp and Wagenaar, Utrecht, Holland; Dr. O. Scott and Mr. P. B. Deverall, Leeds; Dr. L. M. Gerlis, Grimsby; Mr. J. L. Monro, Southampton; and to Professor F. J. Macartney and Mr. J. Stark, London, for permitting us to study necropsy specimens of primitive ventricle. We are indebted to Dr. J. B. Seward of the Mayo Clinic, Rochester, U.S.A., and Drs. C. Mortera, S. J. Hunter, and $M$. J. Tynan, for giving permission to quote their unpublished work. During the course of this investigation, Dr. Beardshaw was supported by a grant from the Board of Governors, National Heart and Chest Hospitals.

\section{References}

Anderson, R. H., Becker, A. E., Wilkinson, J. L., and Gerlis, L. M. (1976). Morphogenesis of univentricular hearts. British Heart Fournal, 38, 558-572.

Assad-Morrell, J. L., Tajik, A. J., and Guiliani, E. R. (1974). Echocardiographic analysis of the ventricular septum. Progress in Cardiovascular Diseases, 17, 219-237.

Beardshaw, J. A., Gibson, D. G., Wright, J. S., Pearson, M. C., and Anderson, R. H. (1976). The echocardiographic diagnosis of corrected transposition (abstract). British Heart fournal, 38, 878.

Chesler, E., Joffe, H. S., Beck, W., and Schrire, V. (1971). Echocardiography in the diagnosis of congenital heart disease. Pediatric Clinics of North America, 18, 1163-1190.

Edie, R. N., Ellis, K., Gersony, W. M., Krongrad, E., Bowman, F., and Malm, J. R. (1973). Surgical repair of single ventricle. Fournal of Thoracic and Cardiovascular Surgery, 66, 350-359.

Felner, J. M., Brewer, D. B., and Franch, R. H. (1976). Echocardiographic manifestations of single ventricle. American fournal of Cardiology, 38, 80-84.

Ferrer, P. L., Gottlieb, S., Kallos, N., Wexler, H., and Miale, A., Jr. (1975). Applications of diagnostic ultrasound and radionuclides to cardiovascular diagnosis. Part II. Cardiovascular disease in the young. Seminars in Nuclear Medicine, 5, 387-418.

Friedberg, D. Z., and Nadas, A. S. (1970). Clinical profile of patients with congenital corrected transposition of the great arteries. A study of 60 cases. New England fournal of Medicine, 282, 1053-1059.

Keutel, J., and Hagenmuller, H. (1976). Echocardiographic diagnosis of corrected transposition of the great arteries. Abstract Book. 7th European Congress of Cardiology, p. 775.

Lacorte, M. A., Fellows, K. E., and Williams, R. G. (1976). Overriding tricuspid valve: echocardiographic and angiocardiographic features. American fournal of Cardiology, 37, 911-919.

Lev, M., Liberthson, R. R., Kirkpatrick, J. R., Eckner, F. A. O., and Arcilla, R. A. (1969). Single (primitive) ventricle. Circulation, 39, 577-591.

Liberthson, R. R., Paul, M. H., Muster, A. J., Arcilla, R. A., Eckner, F. A. O., and Lev, M. (1971). Straddling and displaced atrioventricular orifices and valves with primitive ventricles. Circulation, 43, 213-226.

Maloney, J. D., Ritter, D. G., McGoon, D. C., and Danielson, G. K. (1975). Identification of the conduction system in corrected transposition and common ventricle at operation. Mayo Clinic Proceedings, 50, 387-394. 


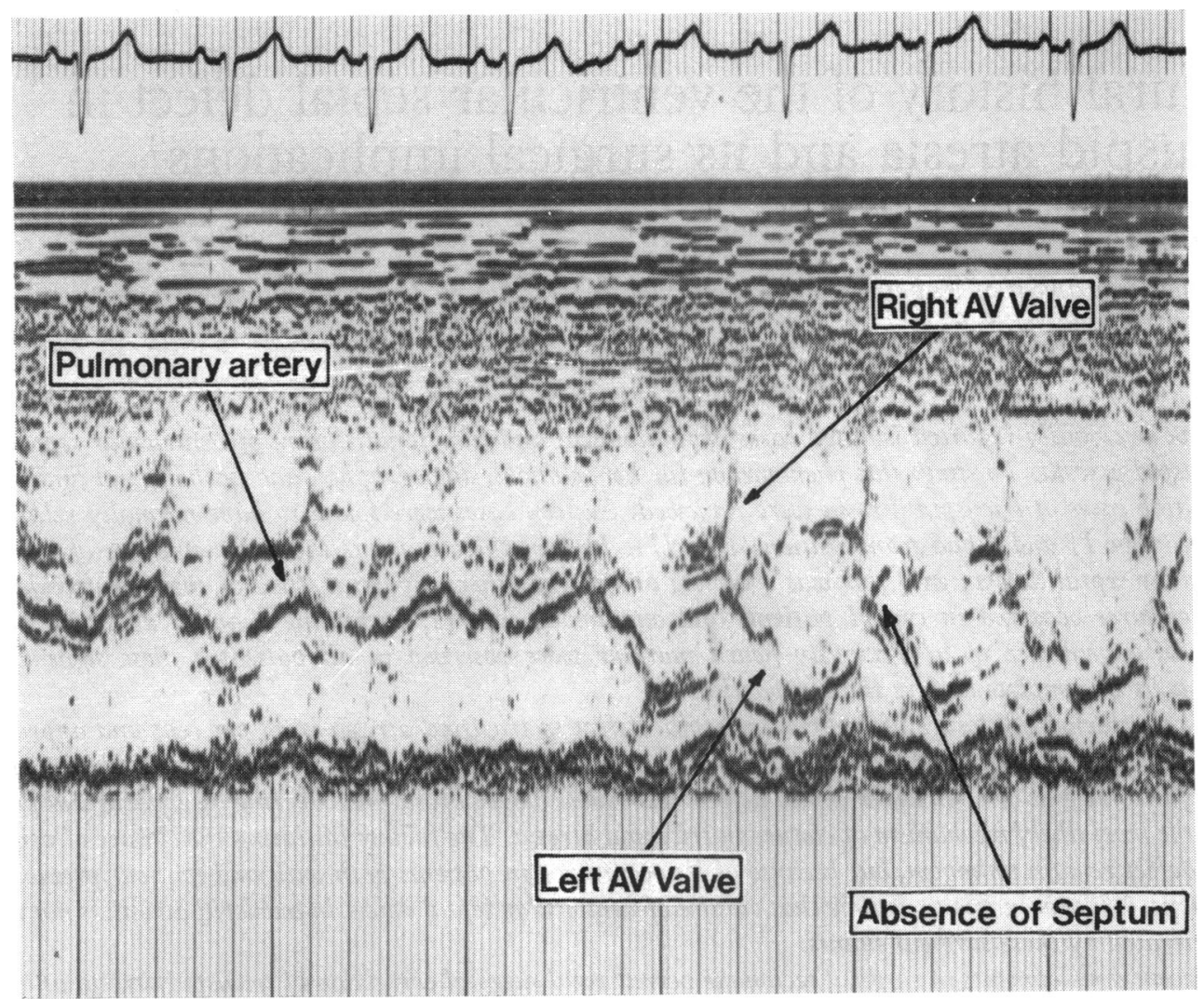

Fig. 9 Echocardiographic scan of a patient with primitive ventricle. Note that the posterior great artery (known to be the pulmonary artery) is in contiguity with both atrioventricular valves, though the echoes from valve to valve are not actually continuous, and that the other criteria for primitive ventricle are also present (compare with Fig. 7 and 8). This patient was diagnosed angiographically as double-outlet right ventricle, but primitive ventricle without outlet chamber was confirmed at operation.

Meyer, R. A., and Kaplan, S. (1973). Non-invasive techniques in pediatric cardiovascular disease. Progress in Cardiovascular Diseases, 15, 341-367.

Rey, C., and Lablanche, J. M. (1976). Echocardiography in corrected transposition of the great vessels. Abstract Book. 7th European Congress of Cardiology, p. 774.

Ruttenberg, H. D. (1970). Corrected transposition of the great arteries. New England fournal of Medicine, 283, 207208.

Seward, J. B., Tajik, A. J., Hagler, D. J., Giuliani, E. R., Gau, G. T., and Ritter, D. G. (1976). Echocardiogram in common (single) ventricle: angiographic-anatomic correlation. American fournal of Cardiology. In the press.

Seward, J. B., Tajik, A. J., and Ritter, D. G. (1975a). Echocardiographic features of straddling tricuspid valve. Mayo Clinic Proceedings, 50, 427-434.
Seward, J. B., Tajik, A. J., Spangler, J. G., and Ritter, D. G. (1975b). Echocardiographic contrast studies. Mayo Clinic Proceedings, 50, 163-169.

Van Praagh, R., Ongley, P. A., and Swan, H. J. (1964). Anatomic types of single or common ventricle in man. Morphologic and geometric aspects of 60 necropsied cases. American fournal of Cardiology, 13, 367-386.

Yacoub, M., Ahmed, M., and Radley-Smith, R. (1975). Use of right atrium to pulmonary artery valved conduit for 'correction' of single ventricle of hypoplastic right heart syndrome. British Heart fournal, 37, 782.

Requests for reprints to Dr. R. H. Anderson, Department of Paediatrics, Cardiothoracic Institute, Brompton Hospital, Fulham Road, London SW3 $6 \mathrm{HP}$. 